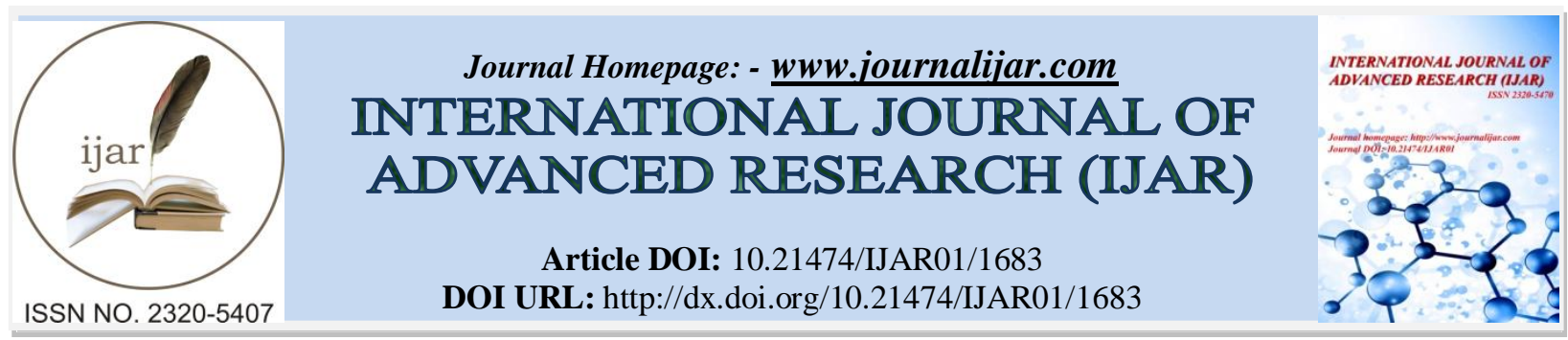

RESEARCH ARTICLE

\title{
GLYCOCONJUGATES OF RAT LUNGS STRUCTURAL COMPONENTS ACCORDING TO LECTIN HISTOCHEMICAL STUDIES DURING EXPERIMENTAL HYPOTHYROIDISM.
}

\author{
Antonina Yashchenko, Lesia Pankevych, Olena Smolkova, Khrystyna Strus, Igor Zastavnyy and Alexander \\ Lutsyk. \\ Department of Histology, Cytology and Embryology, Danylo Halytsky Lviv National Medical University.
}

\section{Manuscript Info}

Manuscript History

Received: 12 July 2016

Final Accepted: 19 August 2016

Published: September 2016

Key words:-

lectins, hypothyroidism, rat lungs

\section{Abstract}

Glycoconjugates of rat lungs structural components according to lectin histochemical studies during experimental hypothyroidism

Antonina Yashchenko, Lesia Pankevych, Olena Smolkova, Alexander Lutsyk, Khrystyna Strus, Igor Zastavnyy

The experimental studies involved 20 sexually mature male rats 180 $200 \mathrm{~g}$. weight, including 10 control and 10 with experimental hypothyroidism induced by the introduction into the food thyreostatic drug merkazolilum at a dose of $5 \mathrm{mg} / \mathrm{kg}$ body weight for 30 days. Histological material was fixed in $4 \%$ neutral formalin. Overview slides 5-7 $\mu \mathrm{m}$ thick were stained by hematoxylin and eosin. Glycoconjugates of the lungs structural components were studied using method of lectin-peroxidase technique. The set of lectins included: concanavalin A (ConA, $\alpha$ DMan specific), peanut lectin (PNA specific for $\beta D G a l(\beta 1-3) D G a l N A c)$, soybean (SBA, specific for a DGalNAc), wheat germ (WGA, specific for DGlcNAc, NeuNAc), elderberry bark (SNA, specific for $\operatorname{Neu} 5 \mathrm{Ac}(\alpha 2-6) \mathrm{Gal} / \mathrm{DGalNAc}$ ), crust of golden rain (LABA, specific for $\alpha$ LFuc). It has been shown, that experimental hypothyroidism is associated with perivascular edema and lectin receptors modification in the lungs structural components, induced the immune processes activation, that resulted in increased number of the SBA- positive alveolar macrophages and BALT-associated LABA positive dendritic cells. Lectin SBA (specific for a DGalNAc) may be considered as one of markers of alveolar macrophages, lectin LABA (specific for $\alpha$ LFuc) as a marker of BALT-associated dendritic cells.

Copy Right, IJAR, 2016,. All rights reserved.

\section{Introduction:-}

Hypothyroidism is one of the most common endocrine diseases, which develops due to deficiency of thyroid hormones. Statistics show an increase in the number of diseases of the endocrine system among the working age population in the world and in Ukraine in particular. The prevalence of hypothyroidism in the world is variously estimated as 1.5-6\% and subclinical-4.3-15\% [Garber et al., 2012; Fatourechi, 2009; Fadeev, Mel'nichenko, 2002]. Hypothyroidism is a syndrome, or complex of changes in majority of organs and systems. Combined thyroid and bronchopulmonary pathology are often found, which significantly complicates diagnostics and often causes 
inadequate and ineffective treatment [Balabolkin, 1998; Balabolkin et al., 2008; Fray, 2000]. It is known, that the lack of hormones is common natural phenomenon that occupies a special place among the world's problems by the number of medical and social consequences for individuals and society [Geelhoed, Glenn, 1999]. Analysis of the literature confirms the steady growth of bronchopulmonary lesions and frequency of endocrine dysfunction in older age groups [Wu et al., 2008; Cappola et al., 2006; Dedov et al., 2006; Pinchera, 2001]. Alveolar hypoventilation of lungs is observed because of muscle discoordination and disorders of the central regulation. Vital lung capacity is slightly decreased due to the weakness of the intercostal muscles or depression of the respiratory center. The lungs are actively involved in the metabolism of glucocorticoids and biogenic amines, who regulate bronchial tonus [Garbrecht et al., 2006; WHO, 2007]. In the scientific literature available to us there are no data concerning the role of glycoconjugates in the secretory processes of lung structural components in norm and on the background of thyroid hypofunction.

The aim - on the basis of lectin - receptor interaction to investigate glycoconjugates of the lung structural components in norm and on the background of experimental hypothyroidism .

\section{Materials and Methods:-}

Research was performed on 20 Wistar rats with mass 180-120g, which were divided into two groups: 1 st - control (10), 2nd - experimental (10). Animals were kept in standard vivarium conditions in compliance with hygiene standards and food ration, manipulations were performed according to the positions of "General ethical principles of the experiments on animals", approved by I National Congress of Bioethics (Kyiv, 2001).

Experimental hypothyroidism was caused by daily administration with food the drug Mercazolyl-Zdorovye (Metimazol) at a dose of $5 \mathrm{mg} / \mathrm{kg}$ body weight. Function control of thyroid gland was performed by determining T3 and T4 hormones in blood serum using radiological method by means of standard sets in radioisotope laboratory of regional clinical hospital and by measuring of thyrocytes' height, also colloid condition has been visually estimated. Animals were scored by decapitation after ether narcosis overdose. Lung pieces were taken from normal and experimental animals and fixed in 4\% neutral formalin. Sections 5-7 $\mu \mathrm{m}$ thick were stained by hematoxylin and eosin for getting panoramic slides. Carbohydrate determinants were examined by the following lectins: concanavalin A (Con A, specific to $\alpha$ DMan, $\alpha$ DGlc), peanut lectin (PNA, specific to $\beta$ DGal ( $\beta 1-3)$ DGalNAs), soybeans (SBA, specific to DGalNAc), wheat germ (WGA, specific to DGlcNAc, NeuNAs), elderberry bark (SNA, specific to Neu5As ( $\alpha 2-6)$ Gal / DGalNAc) crust of golden rain (LABA, specific to $\alpha$ LFuc), labeled by horseradish peroxidase. Control of lectin-binding reaction was done by exclusion of the lectin from protocol, and also by exclusion of inhibition reaction of endogenous peroxidase with methanol. Positive control of the reaction was conducted by the staining of a section of a tissue or cell type that has been determined by previous experiments to be positive for particular lectin labeling (kidney). Visualization was conducted by 3'3-diaminobenzidine tetrahydrochloride ("Sigma", USA) in $\mathrm{H}_{2} \mathrm{O}_{2}$ presence, as previously described [Lutsyk et al. 1989]. Slides were analyzed by means of Carl Zeiss Jena Ng microscope, for photographing digital camera Canon IXUS 700 and photo-system Olympus on the base of BX-41 microscope were used. Statistical analysis was performed, using Microsoft Excel 2003 software.

\section{Results and Discussion:-}

In animals with experimental hypothyroidism decreased level of T3 and T4 hormones has been observed in comparison with animal control group (Figure 1). Overview slides of rat lungs in the control group stained with hematoxylin and eosin showed, that the investigated organ has a typical structure, medium and small bronchi, terminal bronchioles, alveolar ducts and alveolar sacs are observed. Near bronchi lymphoid tissue in the form of follicles, and blood vessels filled with blood cells are located (Figure 2 A, B). Between alveoli in interstitial areas there are small capillaries and cellular elements characteristic for connective tissue.

In the lungs of the animal experimental group it has been noticed swelling of the endothelium, perivascular interstitial edema and vasodilatation filled with blood cells, among which red blood cells dominate. Amount of lymphoid tissue around blood vessels and bronchial tree increases (Figure 2 C, D). Probably in hypothyroidism interstitial edema is caused by processes of products accumulation of protein exchange, glycosaminoglycans, protein derivatives of glucuronic and chondroitinsulfuric acids. 


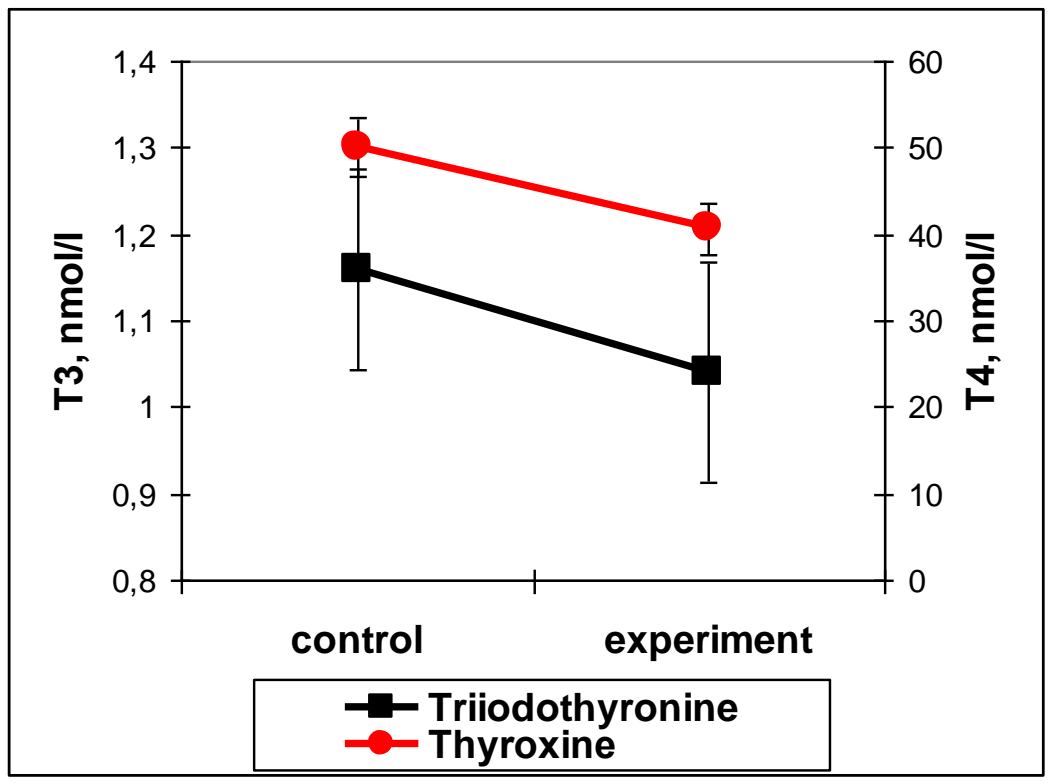

Fig. 1:- Thyroid hormones level in rat blood serum; $p<0.01$
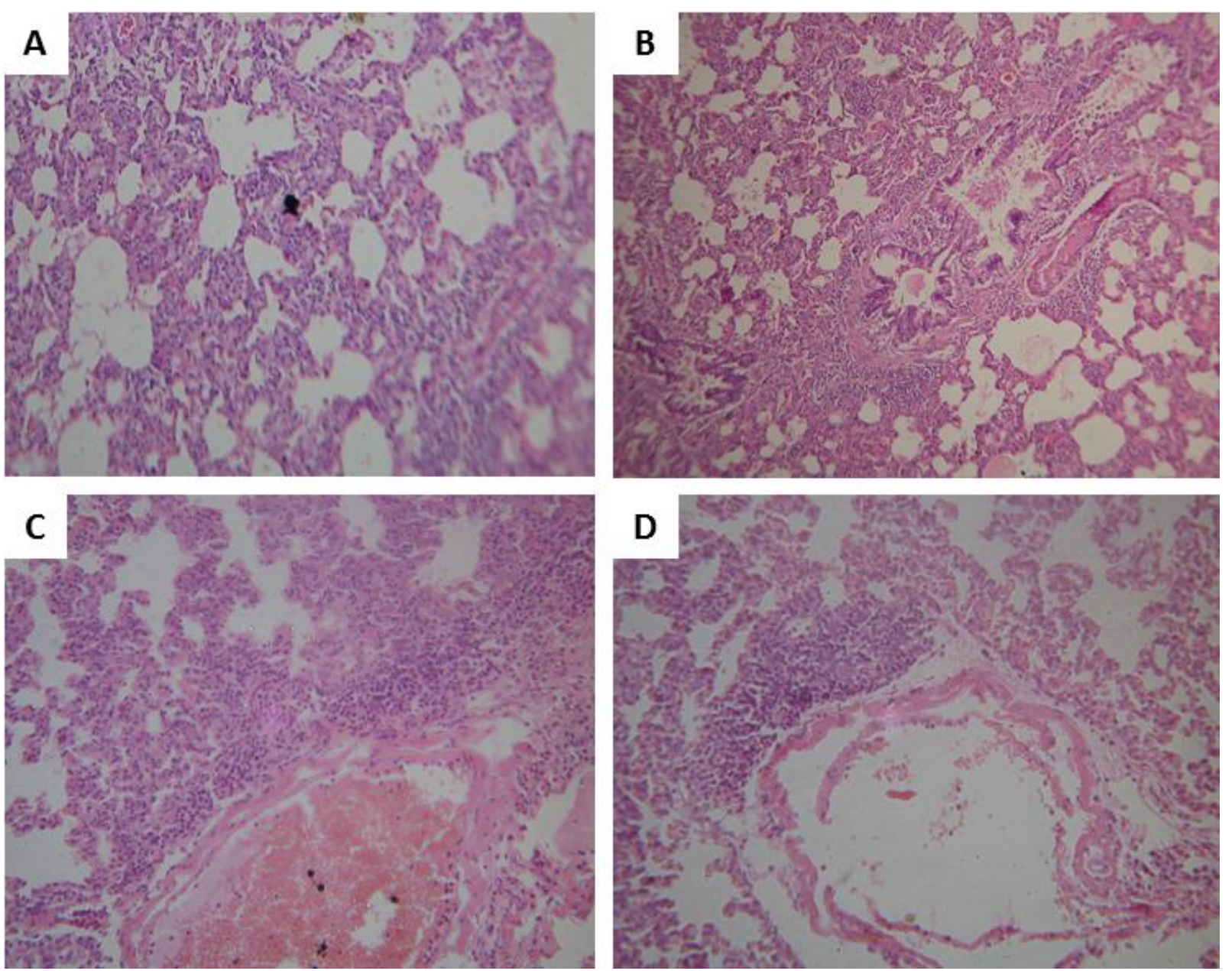

Fig. 2:- Overview slides of rat lung. x400. H\&E. A, B - control; C, D - experimental hypothyroidism (expansion of the vascular lumen and perivascular edema) 
Slides processing of animal lungs by lectins of different carbohydrate specificity in control and experimental group showed specificity of lectins binding in lungs structural components (Table 1).

Table 1:- Lectin receptors of rat lung structural components in the norm and in experimental hypothyroidism

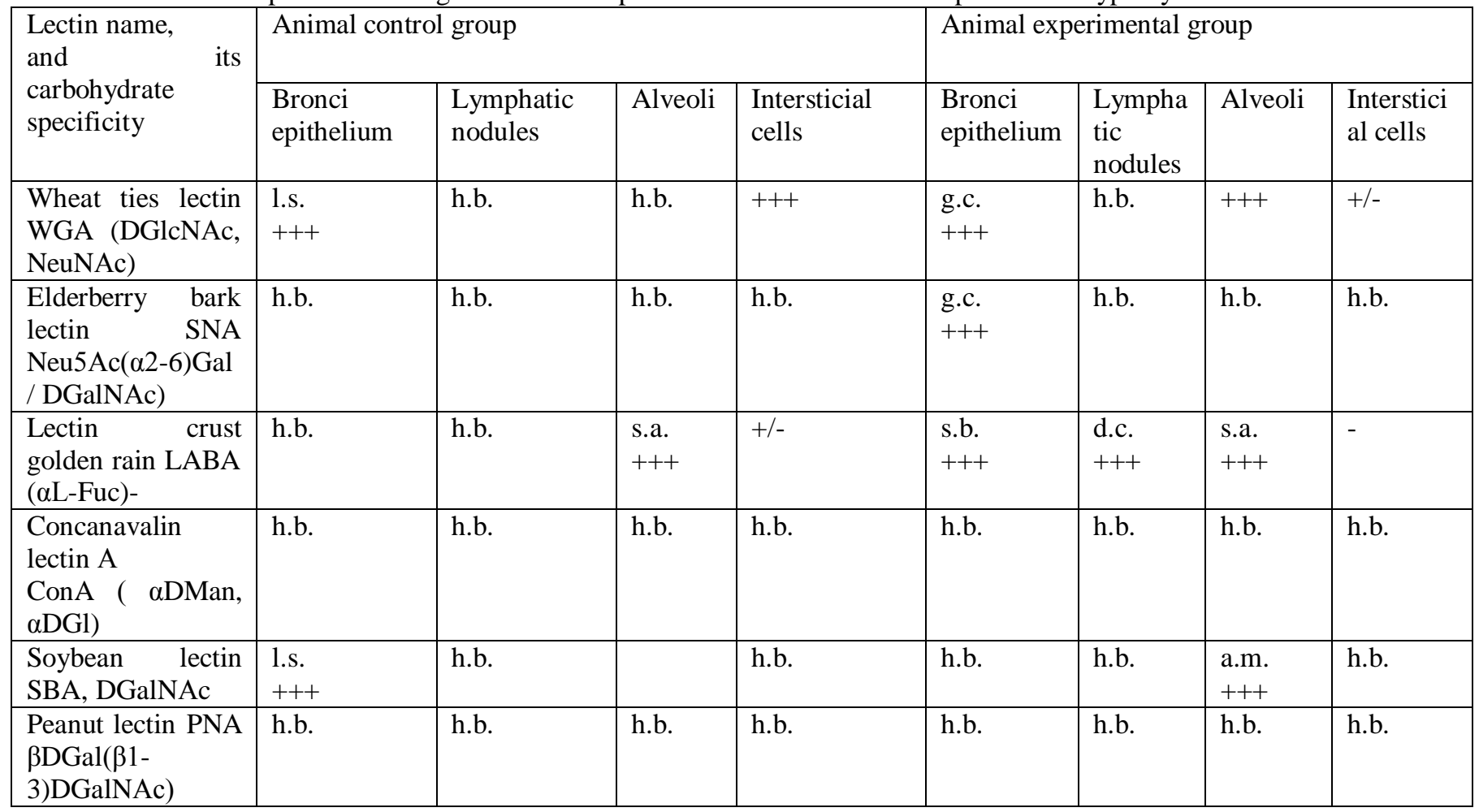

Note: $\quad$ - absence of binding ; + slight reaction; 1.s. - luminal surface;

+++intensive; h.b.- homogenous binding; g.c. - goblet cells; d.c. - dendritic cells;

s.a. - secretory alveolar cells; s.b. - small bronchi; a.m. - alveolar macrophages.

So, DMan- specific lectin ConA in the animal lungs of the control group showed homogeneous binding with components of the respiratory part and conducting portion and interstitium including BALT (Bronchus Associated Lymphoid Tissue) components. In animal lungs of research group ConA lectin binding did not differ from the animals' control group.

WGA lectin revealed high affinity with luminal surface of epithelial cells of small and medium bronchi, clearly outlined vascular endothelium and formed elements in their lumen, and also apical surface of alveolar cells (Figure 4, A, B). In intersticium near alveoli it has been detected cell groups with eccentrically located nucleus and cytoplasmic granularity, that had high expression of that lectin receptors (Figure 4, C, D). The most intensive expression of WGA lectin receptors in animal experimental group was on the apical surface of epithelial cells of the small bronchi and type I alveolar cells (surfactant component), and vascular endothelium (Figure 5. B, C). The appearance of the glycoconjugates' NAcDGlc determinants, WGA lectin receptors as a part of surfactant indicates the peculiarity of its chemical composition, which can affect the permeability of air-blood barrier. Similar changes were observed by [Rudiak, 2005] as part of surfactant in preterm infants. In our case exhibiting of carbohydrate determinants NAcDGlc, suggests about metabolic disorders on the background of experimental hypothyroidism. 

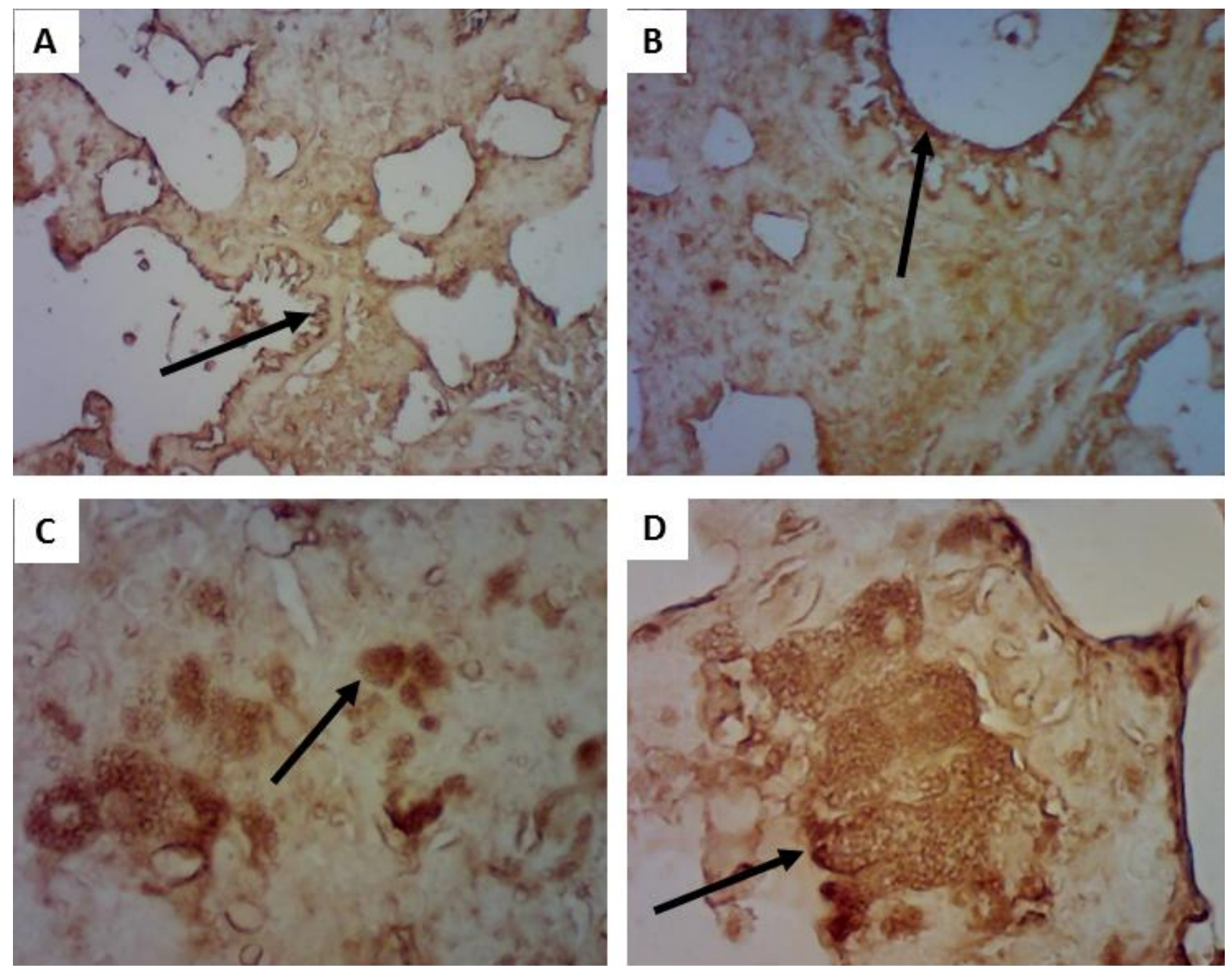

Fig. 4:- WGA lectin receptors in lungs structural components in rat control group.

A, B - lectin receptors on epithelial cells surface of bronchi (B, arrow), terminal bronchioles(A, arrow) and as a part of surfactant on alveolar surface. x 200 (A); x 400 (B); C, D - lectin receptors expression in intersticial cells (C, arrow), bronchial glands (D, arrow). x 600 (C, D). 

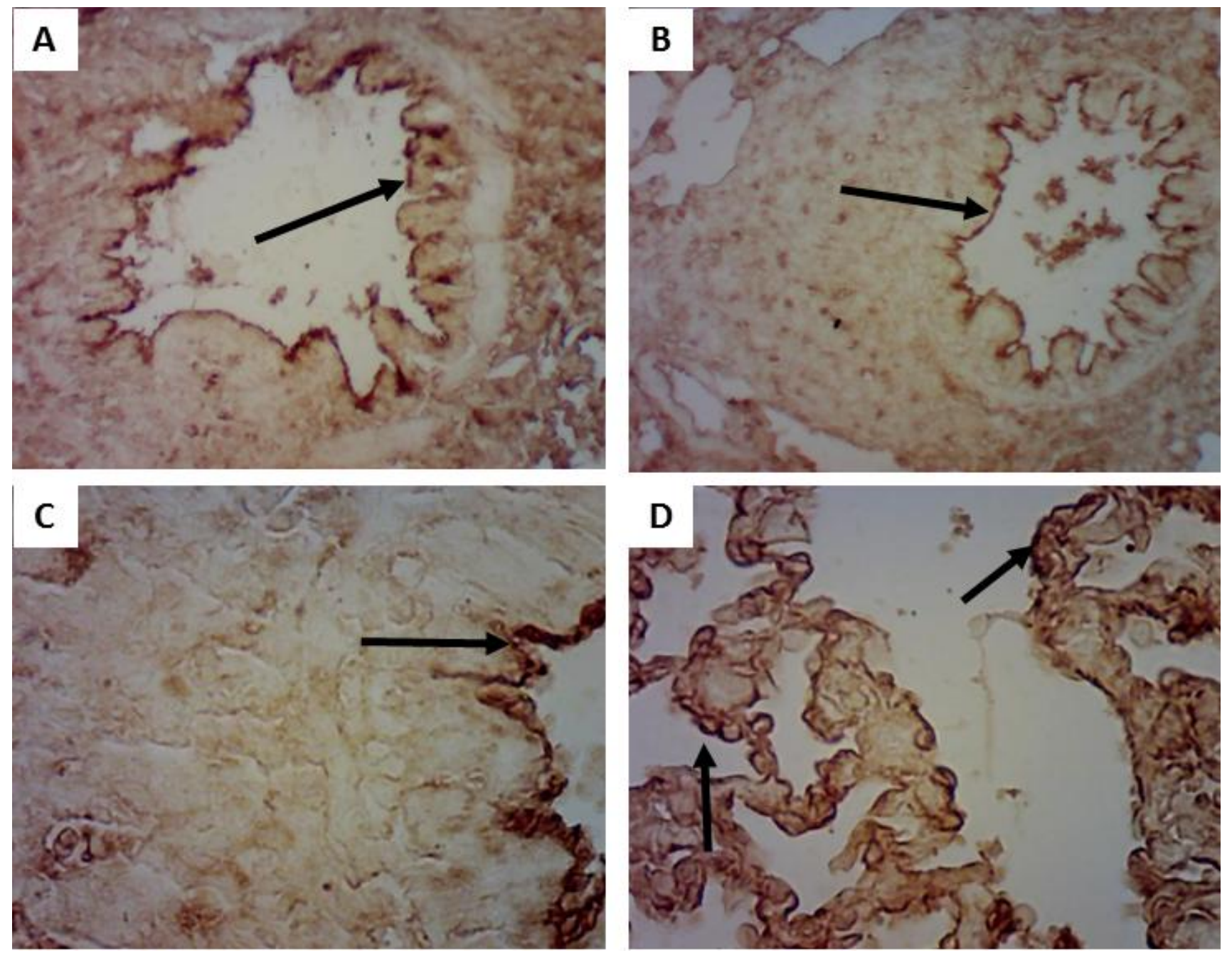

Fig. 5:- Amplification of WGA lectin receptors in epithelial cells of bronchial mucosa (A, B, C, arrows), and on the surface of secretory alveolar cells (D, arrows) in rats on the background of hypothyroidism. x 600.

SBA lectin receptors in animals in the control group are associated with the apical surface of alveoli epithelial cells and apical surface of the cells of bronchial tree (Fig. 3 A, B), while in the experimental group lectin showed relatively high affinity to alveolar cells and alveolar macrophages (Fig. 3, C, D), whose number increased significantly. Increase in the number of alveolar macrophages can be considered as a factor of immune processes stimulation in response to the mercazolilum introduction. 

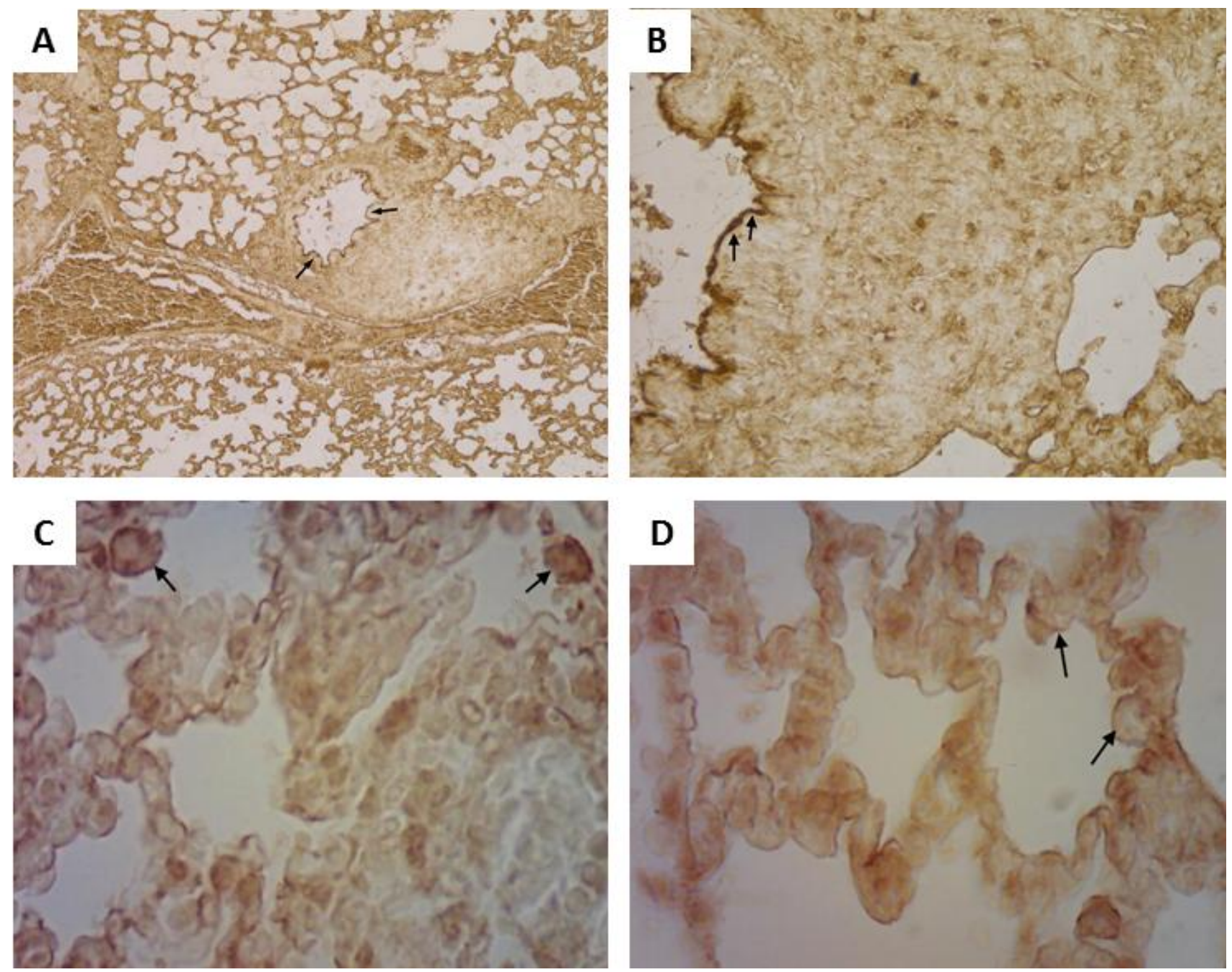

Fig. 3:- A, B - localization of SBA lectin receptors on the luminal surface of epithelial cells of bronchial tree in rat control group (arrows); C, D - SBA lectin receptors on the surface of secretory alveolar cells (D, arrows) and alveolar macrophages (C, arrows); x120 (A); x 300 (B); x 600 (C, D).

Homogenous binding of SNA lectin was observed in animal lungs of control group with lungs structural components, while in experimental group that lectin revealed high affinity to goblet cells of bronchial tree. The rest of structural components demonstrated homogeneity with that lectin binding. Appearance of sialo-specific SNA lectin as part of goblet cells indicates, to our mind, the change in chemical composition of mucociliary barrier and their secretory activity and is one of manifestations of defence mechnanisms.

Fucosespecific LABA lectin in lungs of animal control group revealed affinity to the cells, which were located near alveoli or in alveolar lumen and which contained cytoplasmic granularity affine to that lectin. Besides abovementioned, LABA lectin receptors were identified on the apical surfaces of epithelial cells of some alveoli. In experimental group LABA lectin receptors were revealed in lymphoid follicles near small bronchi, probably, in dendritic cells. Also, expression of those lectin receptors was declared in perinuclear zone of small bronchi epithelial cells, and in secretory alveolar cells. Figdor CG et al. [Figdor et al., 2002] detected, that C-type lectin receptors and lectin-like receptors are located on the surface of dendritic cells.

Currently it is known, that endogenous lectins recognize antigens and regulate the migration of dendritic cells and their interaction with lymphocytes. The appearance of LABA lectin receptors in some cells of lymphoid follicles, whose number is increasing on the background of hypothyroidism, confirms the version of [Figdor et al., 2002] about activation of these receptors in the processes of interaction of lymphoid follicles cellular elements. 
Homogenous binding of PNA lectin was observed in animal lungs of control and experimental group with alveolar cells, in some alveoli their apical surface was outlined.

Our studies have shown, that on the background of experimental hypothyroidism the modification of glycoconjugates in dendritic cells of lymphoid follicles, secretory alveolar cells and goblet cells of the bronchial tree, the endothelial cells of blood vessels are observed.

\section{Conclusions:-}

Experimental hypothyroidism, caused by introduction of merkazolilum at a dose of $5 \mathrm{mg} / \mathrm{kg}$ body weight is accompanied by slight perivascular interstitial edema and modification of lectin receptors in the structural components of the lungs, stimulates the activation of immune processes, that manifest the increase in number of SBA - positive alveolar macrophages and LABA - positive dendritic cells in lymphoid follicles associated with the bronchi. Lectin SBA (specific for a DGalNAc) may be considered as one of markers of alveolar macrophages, lectin LABA (specific for $\alpha$ LFuc) as a marker of BALT-associated dendritic cells.

\section{References:-}

1. Assessment of the iodine Deficiency Disorders and monitoring of their elimination : a guide for programme managers. 3rd edition, Geneva: WHO /Euro/ NUT, 2007:1-98.

2. Balabolkin MI, Klebanova EM, Kreminskaya VM. Differential Diagnostics and Treatment of Endocrine Dis eases, in Rukovodstvo dlya endokrinologov, vrachei shirokogo profilya (Manual for Endocrinologists and Physicians), Moscow: MIA, 2008.

3. Balabolkin MI. Endocrynology. Universum publishing, Moskow, 1998, 352.

4. Cappola, Anne R., et al. Thyroid status, cardiovascular risk, and mortality in older adults. Jama, 2006, 295(9): 1033-1041.

5. Dedov II, Melnichenko GA, Andreeva EN, Arapova SD. Rational pharmacotherapy of the endocrine system deseases and metabolic disorders: guidelines for practical doctors, Litera, Moskow, 2006, 1080.

6. Fadeev VV, Mel'nichenko GA. Hypothyroidism. Guidelines for practical doctors. ZAO «RKI Sovero press», Moskow, 2002.

7. Fatourechi, V. Subclinical hypothyroidism: an update for primary care physicians. Mayo Clinic Proceedings (Review), 2009, 84(1):65-71.

8. Figdor CG, Y van Kooyk, Adema GJ. C-type lectin receptors on dendritic cells and Langerhans cells. Nat Rey Immunol, 2002, 2(2):77-84.

9. Fray JCS. Handbook of Physiology. Section 7: Endocrine system. Volume III: Endocrine regulation of Water and electrolyte balance, Oxford University press, Oxford, 2000, 750.

10. Garber, JR; Cobin, RH; Gharib, H; Hennessey, JV; Klein, I; Mechanick, JI; Pessah-Pollack, R; Singer, PA; et al. Clinical practice guidelines for hypothyroidism in adults, Thyroid, 2012, 22(12): 1200-1235.

11. Garbrecht, Mark R., et al. Glucocorticoid metabolism in the human fetal lung: implications for lung development and the pulmonary surfactant system. Neonatology, 2006, 89(2): 109-119.

12. Geelhoed, Glenn William. Metabolic maladaptation: individual and social consequences of medical intervention in correcting endemic hypothyroidism. Nutrition, 1999, 15(11): 908-932.

13. Pinchera A. Endocrinology and metabolism, McGraw Hill Int., London, 2001, 811.

14. Rudiak O.M. Features and patterns of lectin receptor expression in lungs of premature newborns (29-33 gestational weeks) on the background of some components of metabolic syndrome. Zhurnal AMN Ukrainy, 2005, 11(2):223-237.

15. Wu, Frederick $\mathrm{CW}$, et al. Hypothalamic-pituitary-testicular axis disruptions in older men are differentially linked to age and modifiable risk factors: the European Male Aging Study. The Journal of Clinical Endocrinology \& Metabolism, 2008, 93(7): 2737-2745.

\section{Conflict of interests:-}

The authors declare that they have no conflict of interests. 